\title{
Renewable Energy Source Enactment for Speed Control of BLDC Motor with Proportional Integral (PI) Controller
}

\author{
Soedibyo $^{1 *} \quad$ M. Budi Rahayu Widodo ${ }^{2}$ M. Ashari $^{3}$ \\ ${ }^{1}$ Department of Electrical Engineering, Institute of Technology of Sepuluh Nopember, Indonesia \\ * Email: dibyo_55@yahoo.com
}

\begin{abstract}
This paper present about speed control of Brushless Direct Current (BLDC) Motor $1 \mathrm{~kW}$ in which supplied using Photovoltaic (PV) Array $1.5 \mathrm{~kW}$ that simulated using MATLAB 2016a. Speed control of BLDC exactly depend on voltage condition, so speed control mean voltage control. Furthermore, Proportional Integral (PI) controller will be implemented to get best performance of the system during irradiance change or some load implemented. For detail analysis purpose, the simulation will do in some case such by vary irradiation of PV, Vary the speed reference then vary of load. From simulation result we get the information that dynamic irradiance, load and speed reference will influence the response stability of speed so do Power Consumption, Voltage and Current response.
\end{abstract}

Keywords: Brushless direct current (BLDC) motor, Photovoltaic (PV), Proportional integral (PI) controller.

\section{Introduction}

Brushes Direct Current motors (BLDC) have many advantages such as high efficiency and linear torque-speed characteristics $[1,3]$. other properties are simple to control and plain hardware $[1,2]$. Nevertheless, the main part of the dc motor (brush) is the need of periodic maintenance, because it was eventually use and need to be replaced. The mechanical commutator has other undesirable effects such as sparks, acoustic noise and carbon particles coming from the brushes [3].

Development of technology in power electronic has been influencing Brushless Direct Current Motors or BLDCs are widely enactment in industrial sectors. For example: electric vehicles, heating and ventilation system, motion control system, positioning and actuator system, and many industrial engineering applications [4,5]. There are many of adventage of BLDC such as high efficiency, high torque, low maintenance cost, less noise, higher speed range, long operating life, faster dynamic response and has small size comparing to another DC motors type. inappropriately, speed control method of brushless DC motor is still rather difficult if applied to electric vehicle, and it's price is more expensive others model [3,5-7].

BLDC rather surprisingly, also kind of permanent magnate synchronous motor (PMSM) because it supplied using three phase AC source, even it has different shape of back Emf. BLDC has trapezoidal back emf, and general PMSM has sinusoidal shape.
Principally, Brushless DC motors works similar to the conventional DC motor that work with the mechanical commutation and it was subtituted by an electronic system. There are three sensors to detect position of rotor placed in stator in which distance $60^{\circ}$ each other. When the rotor passed the sensor then they will give the low or high signal than base on this signal. there are six combination of signal inverter to decide which switch will be activated $[1,2,3]$.

This paper present about speed control BLDC using PI controller. Renewable energy source, PV is selected as power source. Simulation divide in two section, section one using constant irradiance and section two using dynamic irradiance $[9,10]$.

Speed of BLDC motor compared into speed reference hence gained using PI controller [5]. The error signal feedbacked into buck boost converter as duty cycle. Ideally, PV operated using Maximum power point tracking (MPPT), so by sensing voltage and current then MPP algorithm will find the maximum power and the result will implement into DC converter [12,13].Nevertheless, control objective is about speed control, in which whenever voltage increase the speed will increase and when the voltage is decrease the speed will decrease also. Then, this objective is opposite with MPPT purpose, finding maximum power (best voltage and current). Consequently, for achieving speed control requirement we have to operate $\mathrm{PV}$ not in maximum power, though depending on speed requirement. Endorsing to dynamic speed requirement, buck boost 
converter is applied which can satisfy voltage value when speed increased or decreased [9,11].

Form simulation result shown that when PV use constant radiation and applied dynamic load, PI Controller can pull back speed into normal condition. Furthermore, when irradiation changed, speed is influenced, and PI control try to normalized this effect. However, gain of proportional and integral need to change depend on load condition, so for future research hybrid intelligent control such us Fuzzy logic, or heuristic method (Particle Swarm Optimization, Genetic Algorithm) are highly recommended $[9,10]$.

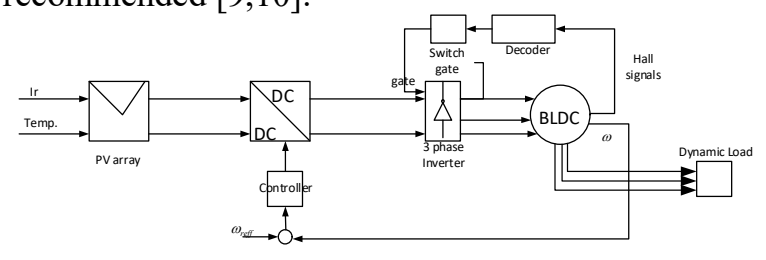

Figure.1 System model

\section{System Modeling}

To get sharp explaination, the system modeling usign MALTAB r2016a, they are consisting of PV Generator model, Buck Boost Converter model, and BLDC motor model.

\subsection{PV Generator}

Photovoltaic (PV) is material or device that have capability to convert energy photon from light (sun) into an electrical voltage and current. Albert Einstein said that photolytic effect indicate that light was discrete particle or energy. Therefore, light can be seen in equation $1[9,11-13]$.

$$
E=h . f=h \frac{c}{\lambda}
$$

Where, plank constant, $h$, is about 6.625 e-34 Js, and velocity of light is about $3 \mathrm{e} 8 \mathrm{~m} / \mathrm{s}$, then $\lambda$ is long of light wave [9]. Generally, principle of photovoltaic is similar with PN junction diode, have an exponential characteristic shown in figure 2 bellow,

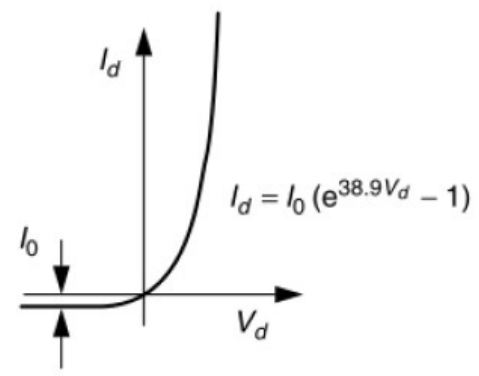

Figure.2 Characteristic of PN junction diode

When voltage supplied into diode positive, then current flowing forward through diode in exponential value like figure 1 , this current can be definite as equation 2 ,

$$
I_{d}=I_{0}\left(\operatorname{Exp}\left(q \frac{V_{d}}{k T}\right)-1\right)
$$

Where,

$$
\begin{array}{ll}
I_{d} & : \text { Current of diode } \\
I o & : \text { Reverse saturation current } \\
q & : \text { Electron charge }(1.602 \mathrm{e}-19 \mathrm{C}) \\
V_{d} & : \text { Voltage across the diode }(\mathrm{V}) \\
k & : \text { Boltzmann's constant }(1.381 \text { e-23 } \mathrm{J} / \mathrm{K}) \\
T & : \text { Junction temperature }(\mathrm{K})
\end{array}
$$

\subsubsection{Eqivalent Circuit of PV}

The eqivalent cicuit of photovoltaic exemplify as current source which parallel with diode, then series and parallel resisor [9](figure 3).

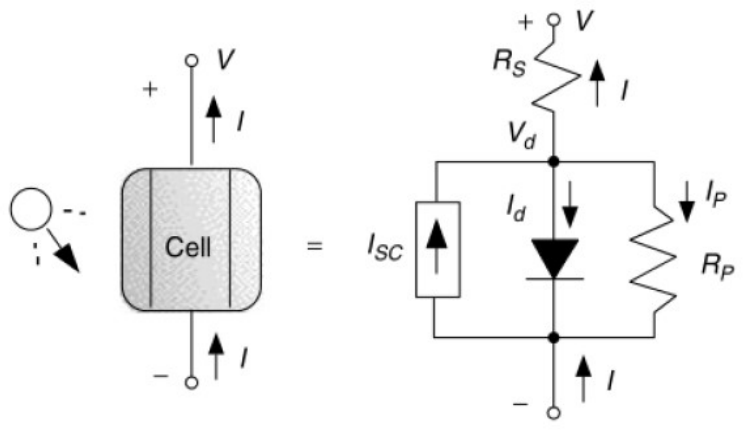

Figure.3 Eqivalent circuit of PV

Base on kirchoff laws, the short circuit current $\left(\mathrm{I}_{\mathrm{sc}}\right)$ is total current that flow to diode $\left(I_{d}\right)$, paralel resistor $\left(R_{p}\right)$ and series resistor $\left(\mathrm{R}_{\mathrm{s}}\right)$, it can be shown in equation 3 ,

$I_{s c}=I+I_{d}+I_{p}$

Base on equation 2 and 3 , current output of PV can be calculated as equation bellow,

$$
I=I_{s c}-\left(I_{0}\left(\operatorname{Exp}\left(\frac{q\left(V_{d}\right)}{k T}\right)-1\right)-\frac{V_{d}}{R_{p}} \quad\right. \text { Eq. (4) }
$$

And the diode voltage, $V_{d}=V+I R_{s}$

Where, $I_{s c}$ is circuit current flowing diode, $R_{s}$ is series resistor, and $R_{p}$ is parallel resistor.

\subsubsection{PV Array Toolbox}

For this simulation we use PV array from library, Sun power SPR-305E-WHT-D with specification shown in table 1 ,

Table 1. Specification of PV Array
Parameter

Maximum power

305. 226 Watt

Cell per module

$96 \mathrm{~N}-\mathrm{Cell}$

Open circuit voltage $\left(\mathrm{V}_{\mathrm{oc}}\right)$

$64.2 \mathrm{~V}$

Short Circuit Current $\left(\mathrm{I}_{\mathrm{sc}}\right)$

$5.96 \mathrm{~A}$

Maximum voltage $\left(\mathrm{V}_{\mathrm{mp}}\right)$ 
JAREE-Journal on Advance Research in Electrical Engineering Volume4, Number 1, April 2020

$\begin{array}{cc}\text { Maximum Current }\left(\mathrm{I}_{\mathrm{mp}}\right) & 5.58 \mathrm{~A} \\ \text { Diode ideal factor } & 0.94504 \\ \text { Shunt resistance }\left(\mathrm{R}_{\mathrm{p}}\right) & 269.5934 \mathrm{ohm} \\ \text { Series Resistor }\left(\mathrm{R}_{\mathrm{s}}\right) & 0.37152 \\ \text { Diode Saturation current }\left(\mathrm{I}_{\mathrm{o}}\right) & 6.3014 \mathrm{e}-12 \\ \text { Light Generated current }\left(\mathrm{I}_{\mathrm{L}}\right) & 6,0092 \mathrm{~A}\end{array}$

Consider to Load (BLDC) is about $1 \mathrm{~kW}$, then we need to arrange the combination of $\mathrm{PV}$ module to reach this value, so in this case we connect the PV with 1 parallel string and 5 series mode. When connect in series it means the current will same with alone module, but the voltage is additional, so the voltage will reach $(54.7 \times 5=273.5 \mathrm{~V})$, so if the current use about $5.58 \mathrm{~A}$, so the power is approximately: 1526,13 Watt during irradiation reach maximum value. Then when irradiation decrease in a half of maximum then the power which generated is about 763.065 Watt. To prove this argumentation, we can plot the characteristic of PV that shown in figure 4.

From figure 1, we can know that when irradiation reach the maximum value $1000 \mathrm{~W} / \mathrm{m} 2$, then the maximum power is about $1.500 \mathrm{~W}$, and when irradiation change a half of maximum value, the power maximum is about $753,1 \mathrm{~W}$

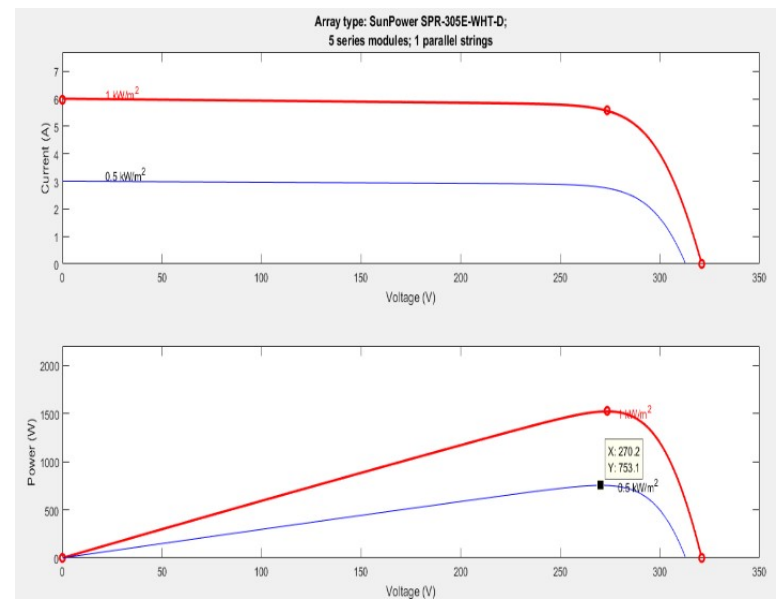

Figure.4. Characteristic of sun-power SPR-305E-WHT-D

\subsection{Buck Boost Converter [8]}

Buck Boost Converter (BBC) well-known as Buck and Boost Converter combination. Some properties of $\mathrm{BBC}$ are Voltage output have opposite polarity with source, when duty cycle of converter less than $50 \%$, the converter will operate as Buck Converter, whereas when duty cycle more than $50 \%$, then the converter will operate as boost converter. Duty cycle is ratio between charging time (on time) and period time of switching $(\mathrm{T})$. In methematically express as equation,

$$
k=\frac{\Delta t_{o n}}{T}
$$

The equivalent circuit of buck boost converter shown in figure 5 bellow:

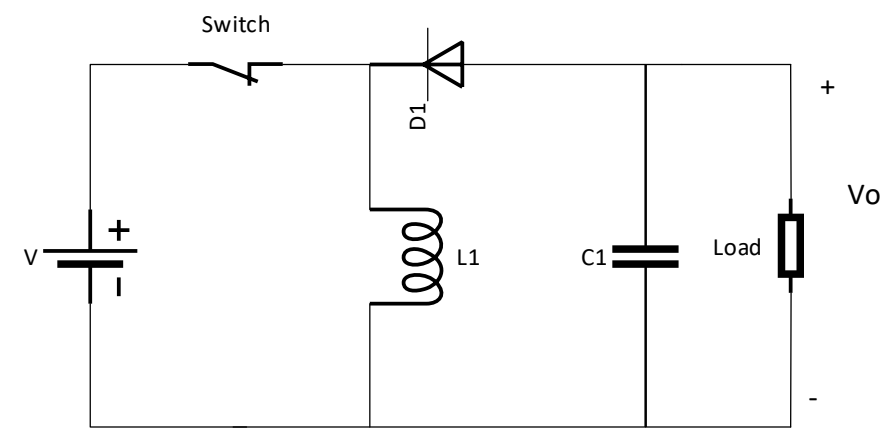

Figure 5. Buck boost converter

Mathematically the voltage output that ensued from this converter shown in equation bellow:

$$
V_{\text {out }}=\frac{k \cdot V_{\text {in }}}{1-k}
$$

Where $V_{\text {out }}$ is voltage output, $V_{\text {in }}$ is voltage input and $k$ is duty cycle. From this equation $100 \%$ value of voltage output is depend on duty cycle, so generate duty cycle is very important to reach design value.

\subsubsection{Charging and Discharging [8].}

When switch close (on) the charging current flow to inductor and diode will block the current (reverse mode), in this case converter in switch on condition. The inductor in charging condition, and current will increase and reach the maximum value when $\mathrm{t}=\mathrm{t} 1$. Time duration of charging can be changing deppend on capacity of inductor, when capacity is too big and time switch on is too short, then charging process is not completed, and induction still empty condition.

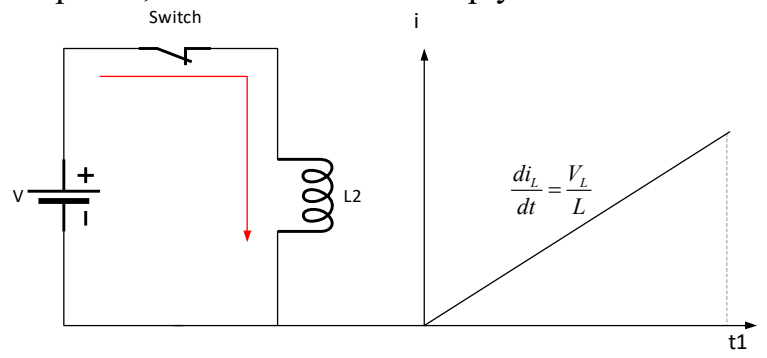

Figure.6 Swich on mode (inductor charging)

The equivalent circuit in figure 6 , can indicated as, $V_{\text {in }}=L \frac{d i_{L}}{d t}=L \frac{\Delta i_{L}}{\Delta t_{o n}}$

$\Delta t_{\text {on }}=L \frac{\Delta i_{L}}{V_{\text {in }}}$

$L \Delta i_{L}=\Delta t_{\text {on }} V_{\text {in }}$

When the current reach the maximum, and time switch on is over, then converter will switch in to off mode, 


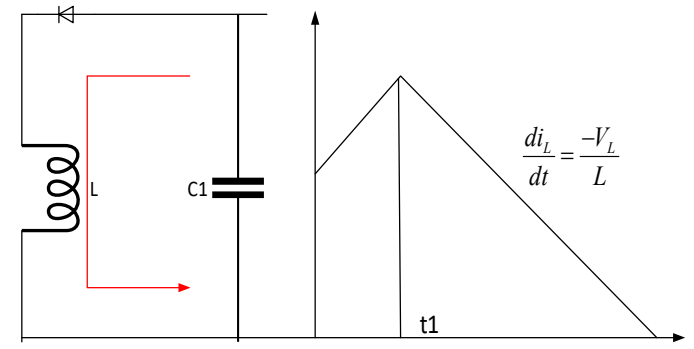

Figure.7 Current flow when discharging mode

$V_{\text {out }}=-L \frac{d i_{L}}{d t}=-L \frac{\Delta i_{L}}{\Delta t_{\text {off }}}$

Eq. (10)

$\Delta t_{\text {off }}=-L \frac{\Delta i_{L}}{V_{\text {out }}}$

By subtitution equation (8) and (9) we got

$V_{\text {out }}=-\frac{\Delta t_{\text {on }} V_{\text {in }}}{\Delta t_{\text {off }}}$

When can manipulate 1 period $(\mathrm{T})$ of charging and discharging, then divided by $\mathrm{T}$, see equation bellow,

$$
\begin{gathered}
\Delta t_{\text {on }}+\Delta t_{\text {off }}=T=\frac{1}{f} \\
\frac{\Delta t_{\text {on }}+\Delta t_{\text {off }}}{T}=\frac{T}{T}=1
\end{gathered}
$$

Then substitution value of duty cycle, to equation 14 , then we get new equation,

$$
\begin{aligned}
& k+\frac{\Delta t_{o f f}}{T}=1 \\
& \Delta t_{\text {off }}=(1-k) T
\end{aligned}
$$

Finally, we prove that the voltage output,

$$
\begin{aligned}
V_{\text {out }} & =-\frac{\Delta t_{\text {on }} V_{\text {in }}}{(1-k) T} \\
V_{\text {out }} & =-\frac{k V_{\text {in }}}{(1-k)}
\end{aligned}
$$

Form final equation we know that minus value of voltage indicate that output of converter has different polarity with voltage source.

\subsubsection{Calculation Inductor and Capacitor}

The converter has some design requirement:

1. Ripple current is about $18 \%$, ripple voltage $1 \%$

2. Can boosting voltage input two times

3. Can decrease voltage input two times

Then, to fulfil the requirement we need calculate the value of inductor and capacitors. Frequency of triangle generation is about $10.000 \mathrm{kHz}$. Base on equation 8,11 , and 13 we can calculate value of inductor:

$L \frac{\Delta i_{L}}{V_{\text {in }}}-L \frac{\Delta i_{L}}{V_{\text {out }}}=\frac{1}{10000}$
$L \Delta i_{L}\left(\frac{1}{V_{\text {in }}}-\frac{1}{V_{\text {out }}}\right)=1 e-4$

$L=54.46 m H$

The value of capacitor can be find using equation bellow

$$
\begin{aligned}
& C=\frac{V_{\text {out }}(1-D)}{8 L \Delta V_{\text {out }} f^{2}} \\
& C=\frac{547(1-0.67)}{8(54 \cdot 4 e-3) \cdot(0.01) \cdot(547)(1 e 4)^{2}} \\
& C=\frac{180,51}{238 \cdot 054 e 3}=0,758 \mu F
\end{aligned}
$$

Value inductors and capacitor is very importance to determine value of ripple current and voltage. Both of value can be implement on simulation:

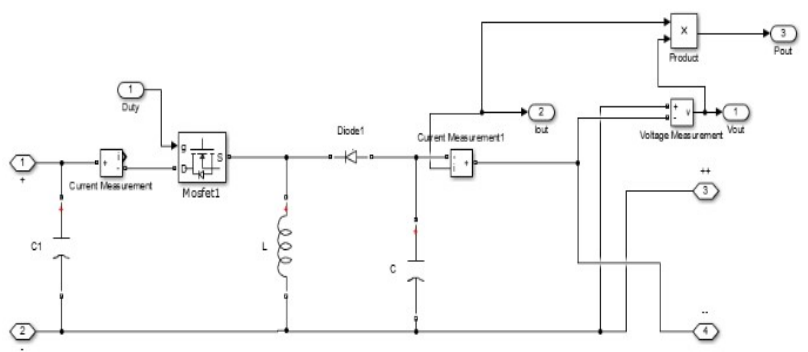

Figure. 8 Buck boost converter simulink model

\subsubsection{Duty Cycle}

Duty cycle is comparation between charging time (on stage) with periode of time (T) during charging and discharging, mathematically duty cycle can calcuate by equation bellow:

$$
k=\frac{t_{\text {on }}}{T} \text {, where } T=t_{\text {on }}+t_{\text {off }}
$$

Buck Boost Converter operated as boost converter, and have ability boost input voltage two times, so we must determine the value of duty cucly by manual calculation.

$$
V_{\text {out }}=-\frac{k V_{\text {in }}}{(1-k)} \text {, then } k=0.67(67 \%)
$$

To construct the duty cycle in MATLAB, we can compare triangle signal and voltage reference. When triangle signal is higher than reference the output will high (1) and when the tingle signal magnitude is less than reference, the output will low (0), this value can be implement using relation operator on Simulink.

By comparing the triangle signal and voltage reference we will get the duty cycle, in MATLAB we can use relation operation to compare. Normally, when voltage refferece is bigger than voltage triangle so the duty will high and when voltage refference is lower than voltage triangle so the duty will low (see figure 9) 
JAREE-Journal on Advance Research in Electrical Engineering Volume4, Number 1, April 2020

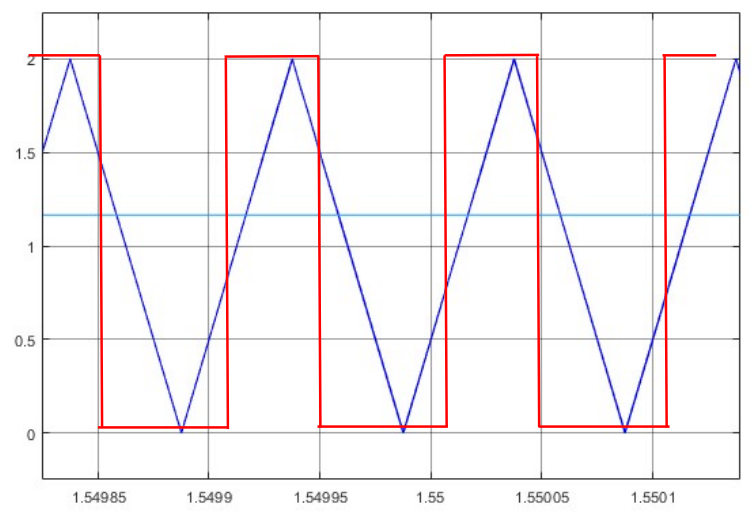

Figure.9 Triangle signal, refference and duty cycle

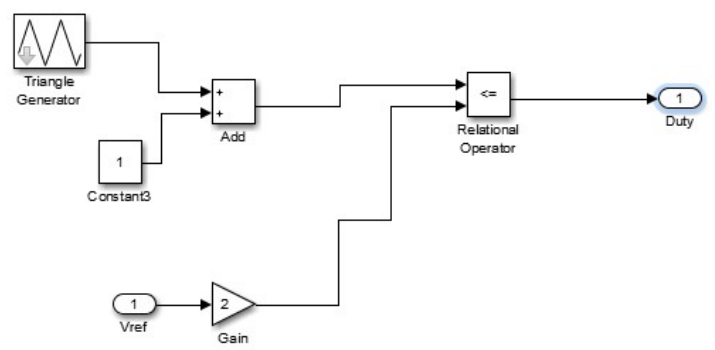

Figure.10 Model of switching signal for duty cycle

\subsection{BLDC Motor}

BLDC's motor construction similar to Synchronous motor, where permanent magnet placed in rotor and winding in stator. There phase source implemented into terminal, only two phases active, one phase remains is unpowered [1,2-7].

\subsubsection{BLDC Eqivalent Circuit}

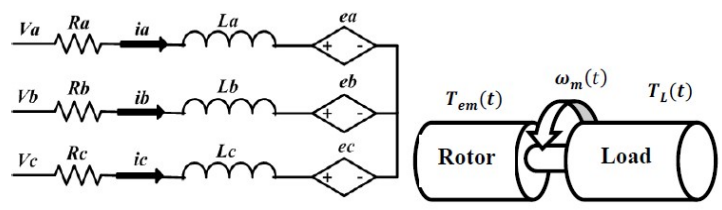

Figure.11 BLDC control scheme

So that the BLDC motor equation can be written as follows:

$$
\begin{aligned}
& V a b=R(i a-i b)+\mathrm{L} \frac{d(i a-i b)}{d t}+(e a-e b) \text { Eq. (19) } \\
& V b c=R(i b-i c)+\mathrm{L} \frac{d(i b-i c)}{d t}+(e b-e c) \text { Eq. (20) } \\
& V c a=R(i c-i a)+\mathrm{L} \frac{d(i c-i a)}{d t}+(e c-e a) \text { Eq. (21) }
\end{aligned}
$$

With value of torque as bellow,

$$
T e m=J \frac{d \omega m}{d t}+\beta \omega m+T L
$$

For simulation study, we use BLDC from MATLAB example, that have specification shown in table 2 bellow. The BLDC have power about 1000 Watt and speed 3000 rpm, in voltage 450 Volt.

Table 2. BLDC parameters Parameters Value Number of Phases 3

$\begin{array}{cc}\text { Back EMF } & \begin{array}{c}\text { Trapezoidal } \\ \text { Torque Tm } \\ \text { Mechanical Input } \\ \text { Stator Phase }\end{array} \\ \text { Resistance (Rs) } \\ \text { Stator Phase } & 8.575 \mathrm{ohm} \\ \text { Inductance }(\mathrm{L}) & \mathrm{H} \\ \text { Flux linkage } & 0.175 \mathrm{~V} . \mathrm{s} \\ \text { Inertia (J) } & 0.8 \mathrm{e}-3\end{array}$

Viscous dumping 1e-3 N.m.s Pole 4

\subsubsection{Hall Sensor and Inverter model}

Similar to synchronous motor, six pulses inverter performed as commutator principle. Rotor position is sensed using Hall effect sensors placed around of stator. when the rotor poles pass near the Hall sensors, they give a high or low signal, indicating the $\mathrm{N}$ or $\mathrm{S}$ pole is passing close to the sensors. The Hall signals have consisted of three digits number change every $60^{\circ}\lceil 2\rceil$.

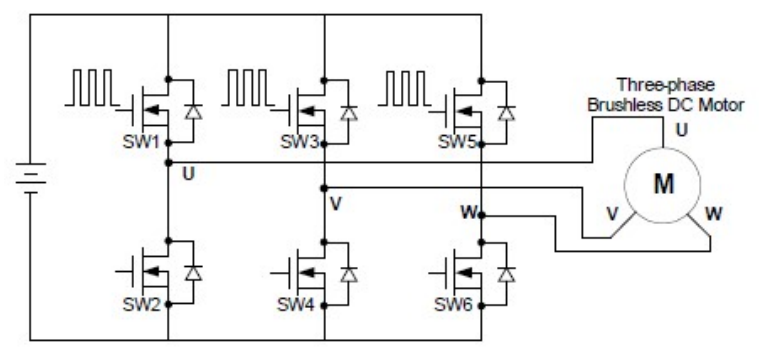

Figure.12 Six pulse inverter for switching

Commonly, there are only two switch that will activated and one other is unpowered, this condition happened depend on EMF that decode from hall sensor.

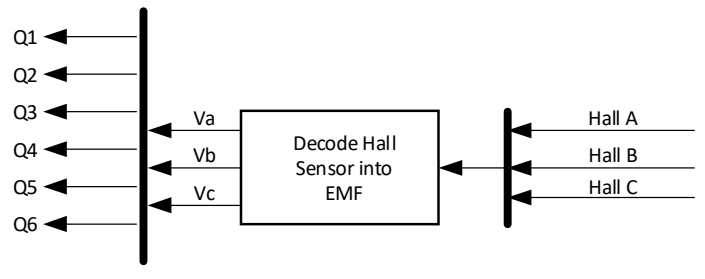

Figure.13 Decode hall into EMF

Table 3. Hall sensor and EMF code H_A H_B H_C E_A E_B E_C 


$\begin{array}{cccccc}0 & 0 & 0 & 0 & 0 & 0 \\ 0 & 0 & 1 & 0 & -1 & 1 \\ 0 & 1 & 0 & -1 & 1 & 0 \\ 0 & 1 & 1 & -1 & 0 & 1 \\ 1 & 0 & 0 & 1 & 0 & -1 \\ 1 & 0 & 1 & 1 & -1 & 0 \\ 1 & 1 & 0 & 0 & 1 & -1 \\ 1 & 1 & 1 & 0 & 0 & 0\end{array}$

Switching output (Q1-Q6) depend on EMF that decode from Hall Sensor code. Hall Sensor consist of 3 digit of value which indicated position of rotor (indicate $\mathrm{N}$ of $\mathrm{S}$ pole). Form this combination decide the EMF that should be powered and unpowered. All combination of EMF shown in table 3 and 4.

Table 4. Hall Sensor and Switching Inverter Corelation

$\begin{array}{ccccccccc}\text { E_A } & \text { E_B } & \text { E_C } & \text { Q1 } & \text { Q2 } & \text { Q3 } & \text { Q4 } & \text { Q5 } & \text { Q6 } \\ 0 & 0 & 0 & 0 & 0 & 0 & 0 & 0 & 0 \\ 0 & -1 & 1 & 0 & 0 & 0 & 1 & 1 & 0 \\ -1 & 1 & 0 & 0 & 1 & 1 & 0 & 0 & 0 \\ -1 & 0 & 1 & 0 & 1 & 0 & 0 & 1 & 0 \\ 1 & 0 & -1 & 1 & 0 & 0 & 0 & 0 & 1 \\ 1 & -1 & 0 & 1 & 0 & 0 & 1 & 0 & 0 \\ 0 & 1 & -1 & 0 & 0 & 1 & 0 & 0 & 1 \\ 0 & 0 & 0 & 0 & 0 & 0 & 0 & 0 & 0\end{array}$

For example, the sensing condition begin from 100, then the EMF that will generated is $+\mathrm{V}, 0,-\mathrm{V}$. Then the EMF will activate which diode that will be operate, in this case only diode Q1 and Q6 operated, and the other is off. Next code is 101, in this condition EMF that will generate is $+\mathrm{V},-\mathrm{V}, 0$ and the switching combination for this condition is Q1 and Q4, so form step 1 to step 2, BLDC rotors already make a move about $60^{\circ}$, and to produce 1 cycle of rotation $\left(360^{\circ}\right)$ the six step of hall code must be running (table 4). For more detail how it works look at figure 14 below
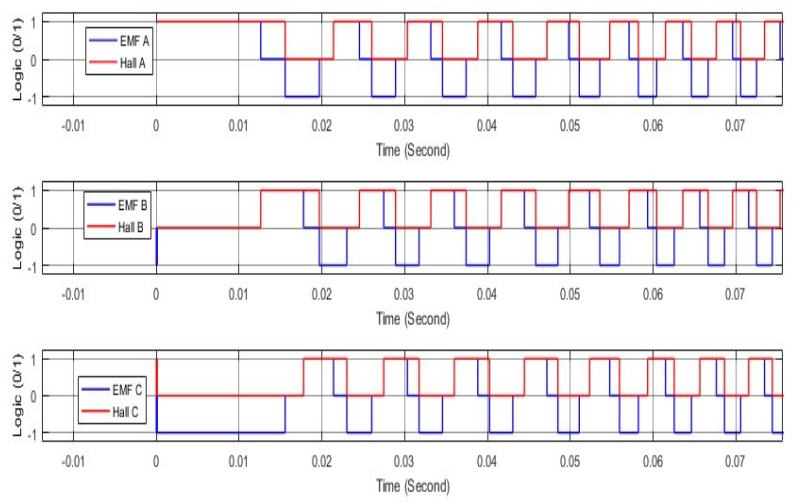

Figure.14 Hall sensor and emf signals

Consider to figure 14, when Hall A, B,C (100) then EMF $\mathrm{A}, \mathrm{B}$ and $\mathrm{C}$ logic is about $(+\mathrm{V}, 0,-\mathrm{V})$ and to prove which switch that will be activated. , please take care on figure 15 bellow:

Different to synchronous motor or induction machine which use 3 switching in the same time, in BLDC motor, only 2 switching that will activated. And form figure 15, only Q1 and Q6 that in high condition, and the others is low. So, our BLDC was work properly
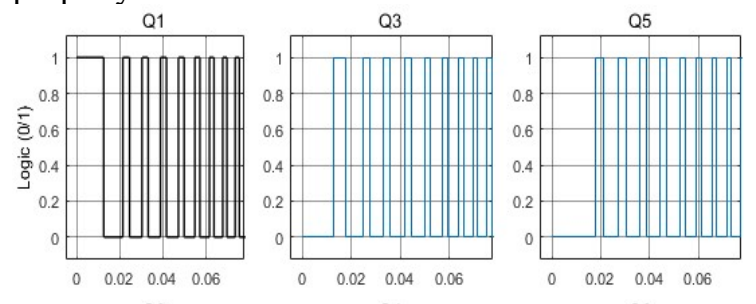

Q2
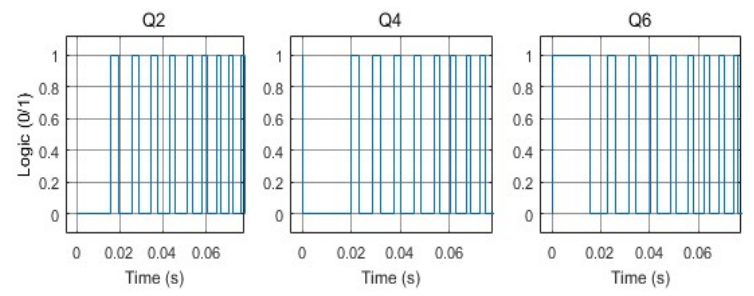

Figure.15 Inverter Switching Signal

\section{Control Design}

When load applied into system, then the system will response this condition, speed decreased. To pullback the speed response into normal condition, we need put control system. For this simulation we are using PI Controller. PI Controller consist of parametes proportional (P) and Integral (I), where block diagram shown in figure 16 below:

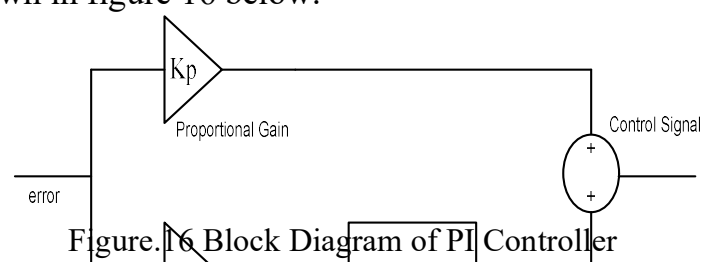

Combihation it and I controllerd callect as PI controller. PI controller has characteristic accelerate rise time and reduce steady state error [4,5]. Matenthatichally PI controller express as equation below:

$u(s)=\left(K_{p}+\frac{K i}{s}\right) e(s)$

Also can be express in time domain is shown,

$u(t)=\left(K_{p} e(t)+K i \int e(t) d t\right)$

$u(t)=K_{p}\left(e(t)+\frac{1}{T_{i}} \int e(t) d t\right)$ and $T_{i}=\frac{K_{i}}{K_{p}}$

Where $K_{p}$ (gain proportional) and $K_{i}$ (gain integral), $e(t)$ is error, and $T_{i}$ is time constant of integral.

\section{Simulation dan Study Cases}


For detail analysis, simulation will do in some condition. There are six condition that we will evaluate, for example:

1. Irradiation is constant, no load condition, full speed

2. Irradiation is constant, dynamic load, full speed

3. Irradiation is constant, with dynamic load, half speed

4. Irradiation is dynamic, no load condition, full speed

5. Irradiation is dynamic, dynamic load, full speed

6. Irradiation is dynamic, with dynamic load, half speed

Simulation result that will be collected is Speed Response of BLDC, Power of PV and Motor, Voltage of PV and Motor

\subsection{Irradiation is Constant, No Load, Full Speed}

For first simulaiton, we will run BLDC system using constant Irradiation $1000 \mathrm{~W} / \mathrm{m}^{2}$, and temperature $25^{\circ}$, see figure 17 .
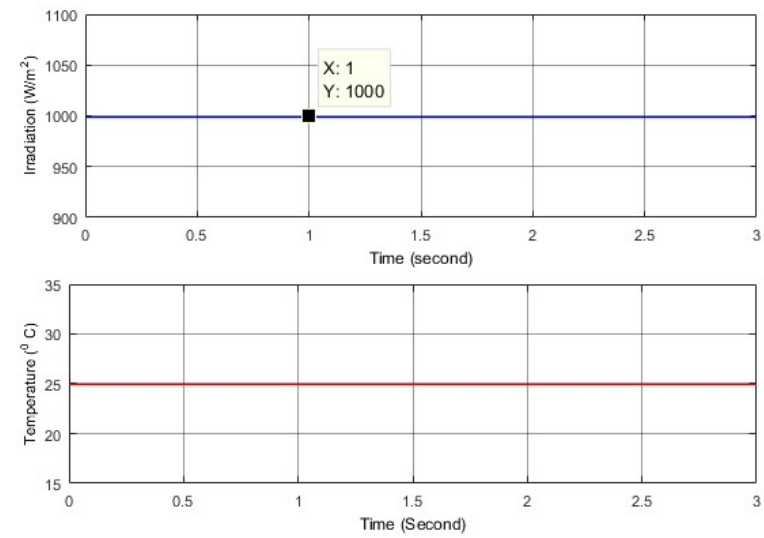

Figure.17 Constant Irradiation and Temperature

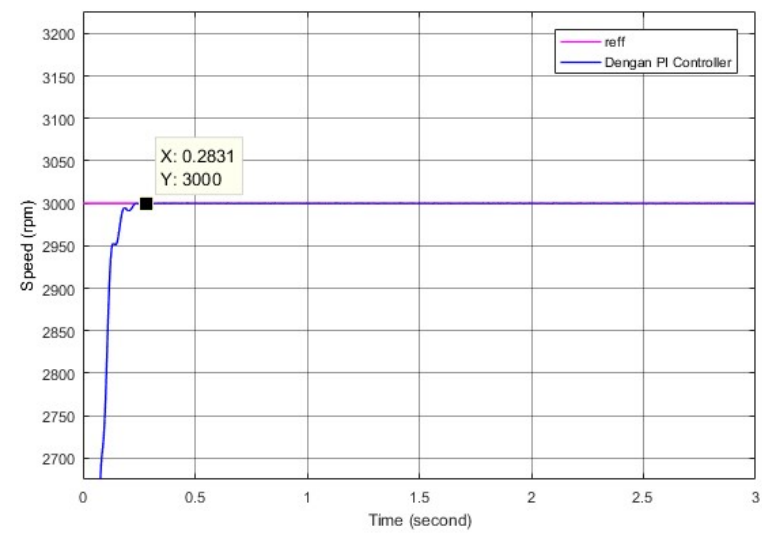

Figure.18 Speed Response

The speed response for first condition shown in figure 18 . The steady state response, when speed 3000 rpm, reach during 0.28 second. And overall there is no disturbance response during this time

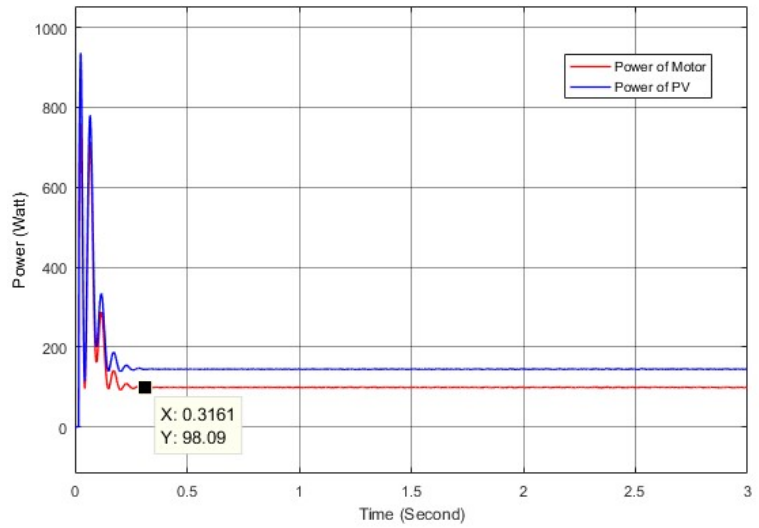

Figure.19 Power of PV and Motor Responses

When fist time starting, the power will show overshoot response, becasuse current starting is very high (5 to 7 times nominal current) then reach the steady state condition. From figure 19, we know that steady state of power response is 0.3161 second, and the power of motor is about 98.09 Watt.

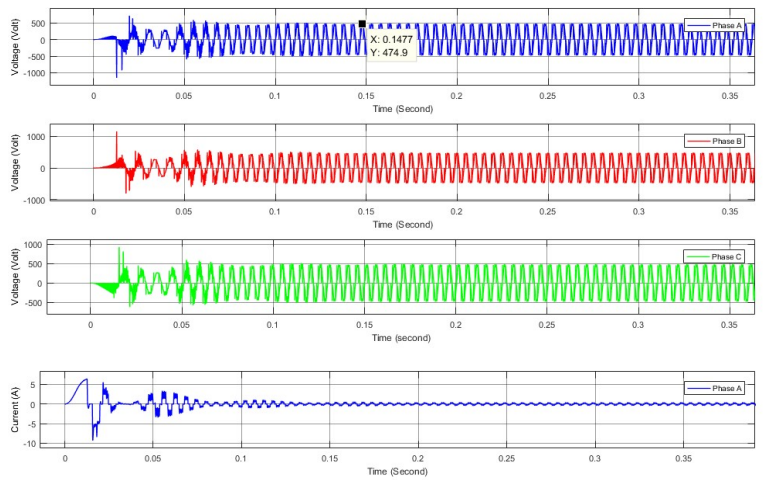

Figure.20 Votlage and Current of PV

When no load condition, voltage of motor is about 474.9 peak to peak, and current almost zero. Starting current is about 5 ampere.

From simulation result we know that, when irradiance constant $\left(1000 \mathrm{~W} / \mathrm{m} 2,25^{\circ} \mathrm{C}\right)$, no load implemented, and in full speed setting (3000 rpm), the power energized by $\mathrm{PV}$ is about 144 Watt, Voltage energized by $\mathrm{PV}$ is $445.7 \mathrm{~V}$, and Current $0.32 \mathrm{~A}$. whereas speed reach steady state condition in 0.29 second. PV power and Motor power have diferrent value because there are many losses happened (electronic parts). 
JAREE-Journal on Advance Research in Electrical Engineering Volume4, Number 1, April 2020
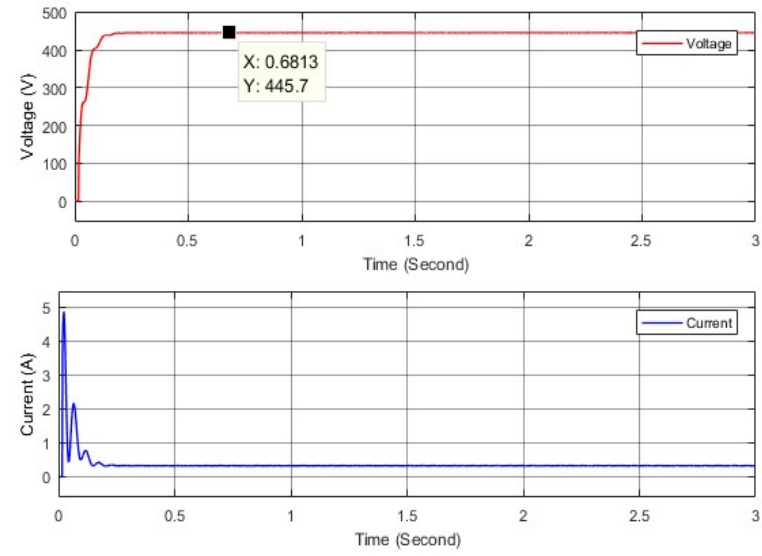

Figure 21. PV Voltage and Current Response

\subsection{Irradiation is Constant, Dynamic Load, Full speed}

Second condition using constant irradiance (Irradiation $1000 \mathrm{~W} / \mathrm{m}^{2}$, in temperature $25^{\circ}$ ), but implemented load is applied $1 \mathrm{Nm}(1.5 \mathrm{~s})$ and $3 \mathrm{Nm}(2.5 \mathrm{~s})$.

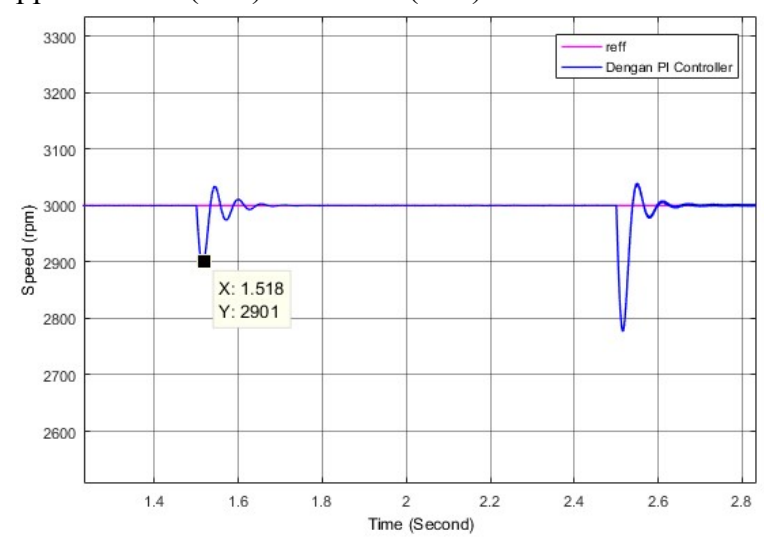

Figure.22 Speed Response with Load $1 \mathrm{Nm}$ and $3 \mathrm{Nm}$

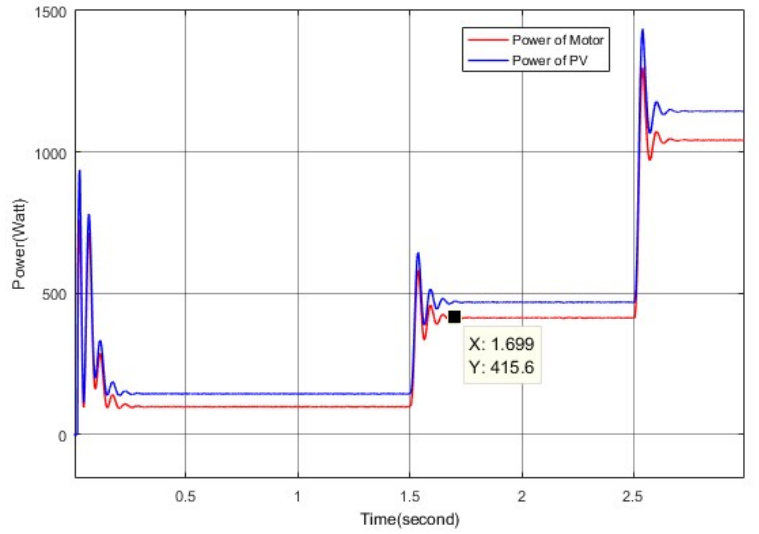

Figure.23 Power Consumption of Motor

Generally response during no load implemented is similar as before, but if we comparing deeper during load already enacment in $1.5 \mathrm{~s}$ and $2.5 \mathrm{~s}$, there are oscilation response. Lowest response magnitute of speed is about 2.901 rpm (decrease almost $100 \mathrm{rpm} / 3 \%$ ) and $2.783 \mathrm{rpm}$ (decrease about $220 \mathrm{rpm} / 7 \%$ ). The speed response pull back to normal condition for each load is about 1.6 second and 2.7 second. So Lest look at power and voltage response

We can do all the simulation condition and get the result as table bellow:

Teble 5. Performance of power and speed control by vary of load and irradiance

\begin{tabular}{|c|c|c|c|c|c|c|c|c|c|c|c|c|c|}
\hline \multirow{2}{*}{\multicolumn{2}{|c|}{ Parameters }} & \multicolumn{3}{|c|}{ Full Speed } & \multicolumn{2}{|c|}{ Half Speed } & \multicolumn{3}{|c|}{ Full Speed } & \multicolumn{2}{|c|}{ Half Speed } & \multicolumn{2}{|c|}{$\begin{array}{c}\text { Irradiance } \\
\mathbf{W} / \mathbf{m}^{2}\end{array}$} \\
\hline & & \multicolumn{5}{|c|}{ Ir constant, Dyn Load } & \multicolumn{5}{|c|}{ Ir. Dyn and Dyn. Load } & $\begin{array}{r}1000 \\
-500\end{array}$ & $\begin{array}{l}500- \\
1000\end{array}$ \\
\hline \multicolumn{2}{|c|}{ Load } & $\mathbf{0}$ & 1 & 3 & 1 & 3 & $\mathbf{0}$ & 1 & 3 & 1 & 3 & & \\
\hline \multirow{3}{*}{ PV } & $\begin{array}{l}\text { Power } \\
\text { (W) }\end{array}$ & 144.6 & 467.6 & 1,143 & 197.6 & 544.9 & 144.6 & 468.1 & 1,143 & 197.6 & 544.9 & - & - \\
\hline & $\begin{array}{l}\text { Voltage } \\
\text { (V) }\end{array}$ & 445.7 & 458.2 & 484.1 & 230.3 & 247 & 445.7 & 458.2 & 483.7 & 230.3 & 247 & - & - \\
\hline & $\begin{array}{l}\text { Current } \\
\text { (A) }\end{array}$ & 0.32 & 1.02 & 2.36 & 0.86 & 2.20 & 0.32 & 1.02 & 2.36 & 0.85 & 2.20 & - & - \\
\hline \multirow{3}{*}{$\begin{array}{l}\text { Moto } \\
\mathrm{r}\end{array}$} & $\begin{array}{l}\text { Power } \\
\text { (W) }\end{array}$ & 98.1 & 415.6 & 1,041 & 182 & 496.2 & 98.64 & 412.6 & 1,041 & 181.9 & 495.8 & - & - \\
\hline & $\begin{array}{c}\text { Voltage } \\
\text { (V) }\end{array}$ & 339.21 & 397.1 & 497.2 & 185.5 & 317 & 339.2 & 371.86 & 539.9 & 196.4 & 332.1 & - & - \\
\hline & $\begin{array}{l}\text { Current } \\
\text { (A) }\end{array}$ & 0.29 & 0.86 & 2.12 & 0.68 & 2.19 & 0.29 & 0.89 & 2.69 & 0.71 & 1.92 & - & - \\
\hline \multicolumn{2}{|c|}{ Delta Power (W) } & 46.51 & 52.0 & 102 & 15.6 & 48.7 & 45.96 & 55.50 & 102 & 15.7 & 49.1 & - & - \\
\hline $\begin{array}{c}\text { Spee } \\
\mathrm{d}\end{array}$ & $\begin{array}{c}\mathrm{t} \\
\text { overshoot } \\
(\mathrm{s})\end{array}$ & - & 1.52 & 2.53 & 1.52 & 2.51 & - & 1.52 & 2.52 & 1.514 & 2.51 & 1.02 & 2.02 \\
\hline
\end{tabular}


JAREE-Journal on Advance Research in Electrical

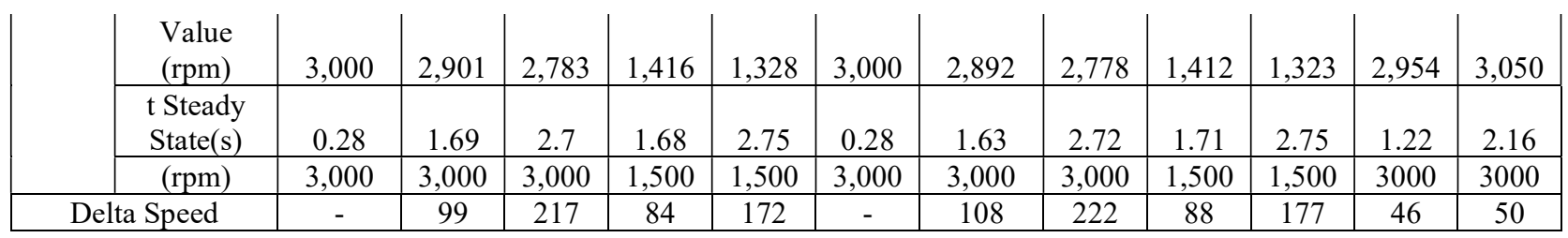

\section{Conclusion}

From many of simulation condition finally we can get some summary, they are:

1. BLDC speed depend on voltage that implemented, when the voltage increased the speed will increase, in other side, when voltage decreased the speed will be decrease also, so it was very important to control voltage of BLDC to get best performance.

2. Dynamic Irradiance influence of speed response, especially during low irradiance, the voltage drops. If the power source is not big enough it will become big problem, but if the load is still under capacity of PV there is no significant influence.

3. Dynamic load has big disturbance on speed response, so do with power consumption and voltage or current performance.

4. Lower speed made big effect in BLDC system, especially when the nominal specification is higher than running requirement. So, it was very important to evaluate, whether setting requirement is far away from specification or not. Normally, the lower speed made bigger power losses.

5. PI Controller have good performance to control system in many cases, such as dynamic load, dynamic irradiance, and dynamic speed reference, even the time to reach steady state value was need to increased.

6. For future research implementation of Artificial Intelligence is highly recommended to get parameters of Proportional dan Integral, for example Fuzzy Logic, Particle Swarm Optimization, Genetic Algorithm, etc.

\section{Acknowledgments}

This work was supported by the Faculty of Electrical Engineering, Institute of technology of Sepuluh Nopember, Surabaya, especially Conversion Energy Laboratory.

\section{References}

[1] S. Baldursson, "BLDC Motor Modelling and Control-A Matlab ${ } /$ Simulink $®$ Implementation," Master Degree, International masters program in Electric Power Engineering ,CHALMERS TEKNISKA HÖGSKOLA, Institutionen för Energi och Miljö, Göteborg, Sverige, 2005.

[2] A. G. T. Shivraj SDudhe, "MATHEMATICAL MODELLING AND SIMULATION OF THREE PHASE BLDC MOTOR USING MATLAB/SIMULINK," International Journal of Advances in Engineering \& Technology, IJAET, vol. 7, pp. 1426-1433, 2015.

[3] J. Z. Y. Yu, "Brushless DC Motor Fundamentals," 2011.

[4] P. R. P. Akhila M, "Brushless DC Motor Drive with Regenerative Braking using Adaptive Neuro based Fuzzy Inference System," International Conference on Electrical, Electronics, and Optimization Techniques (ICEEOT),IEEE, p. 16, 2016.

[5] M. B. F. Arman Jaya, Era Purwanto, Farid Dwi Murdianto, Muhammad Rizani Rusli, "Design of PIDFuzzy for Speed Control of Brushless DC Motor in Dynamic Electric Vehicle to Improve Steady-State Performance," International Electronics Symposium on Engineering Technology and Applications (IES-ETA), 2017.

[6] R. S. SudhanshuMitra1, Ravi Prakash3, "Modeling and Simulation of BLDC Motor using MATLAB/SIMULINK Environment," International Research Journal of Engineering and Technology (IRJET), vol. 02, 2014.

[7] M. A. B.Tayade, "Modeling and Simulation of A Bldc Motor By Using Matlab/Simulation Tool," IOSR Journal of Electrical and Electronics Engineering, 2014.

[8] I. M. E. Mochammad Ashari Prof., Ph.D,IPU, "Desain Converter Elektronika Daya," 2017

[9] G. M. Masters, Renewable and Efficient Electric Power Systems. 2004.

[10] S. Solar, "Solar Crystalline Silicon Technology." [Online]. Available: http: //www.us.schott.com/photovoltaic/english/About_pv/tech nologies/crystalline.

[11] A. H. Eldin, "A Review on Photovoltaic Solar Energy Technology and its Efficiency," no. December, 2007.

[12] S. E and C. J, String Ribbon Growth Technique",(Evergreen Solar, Sovello) Growth Vol 82, pp. 177. 1987.

[13] C. K, L, P. P, D, and V.Dutta, No TitleThin - film solar cell overview", Prog. Photovoltaic: Res.,vol. 12, pp. 6992. 2004 